\title{
GESTÃO AMBIENTAL: ABORDAGEM SISTÊMICA
}

Thadeu Henrique Witkowski, Munir Jorge Felício

Universidade do Oeste Paulista, Mestrado em Meio Ambiente e Desenvolvimento Regional - MMADRE, Presidente Prudente, SP. E-mail: thadeu henrique@hotmail.com

\section{RESUMO}

A gestão ambiental consiste em gerir e administrar a escassez dos recursos naturais prevendo a manutenção das condições imprescindíveis para a sobrevivência das gerações presentes sem comprometer a qualidade da mesma sobrevivência das futuras gerações. É fundamental compreender a gestão ambiental numa concepção sistêmica em que todas as abordagens estejam contempladas e analisadas, considerando-a inerentemente multidimensional. Este texto objetiva compreender a gestão ambiental numa concepção sistêmica em que todas as abordagens estejam contempladas e analisadas. Para tanto, o desenvolvimento deste trabalho fora constituído em análises conduzidas por autores clássicos e a atualização por pesquisadores contemporâneos. Na abordagem sistêmica a gestão ambiental visa uma transformação sustentável, na qual se respeite e use de maneira criativa os sistemas ambientais naturais, adequando-se a lógica produtiva à lógica de funcionamento dos sistemas naturais, e assim predomine a sustentabilidade do sistema. Palavras-chave: Gestão ambiental; pensamento sistêmico; multidimensionalidade.

\section{AMBIETAL MANAGEMENT: SYSTEMIC APPROACH}

\section{ABSTRACT}

Environmental management is to manage and administer the scarcity of natural resources providing for the maintenance of the preconditions for the survival of present generations without compromising the quality of the very survival of future generations. It is essential to understand the environmental management in a systemic conception that all approaches are addressed and analyzed, considering inherently multidimensional. This paper aims to understand the environmental management in a systemic conception that all approaches are addressed and analyzed. Therefore, the development of this work was made in analyzes conducted by classical authors and updating by contemporary researchers. In systemic approach to environmental management aims at a sustainable transformation, in which respect and use creatively natural environmental systems, adapting to the productive logic to the logic of operation of natural systems, and so predominates the system's sustainability.

Keywords: Environmental management; systems thing; multidimensionality. 


\section{INTRODUÇÃO}

Este texto participa das discussões sobre a gestão ambiental, considerado fundamentalmente compreende-la numa concepção sistêmica em que todas as abordagens estejam contempladas e analisadas. Através do pensamento sistêmico é possível para esclarecer que as relações estabelecidas pelo modelo econômico capitalista e sua dinâmica de contínua evolução, reprodução e acumulação, tem-se demonstrado incompatível com a capacidade de suporte planetário por entender que os recursos naturais são infinitos. A racionalidade ambiental demonstra, por essas razões, que a crise ambiental pode também ser compreendida como o resultado da concepção reducionista, mecânica, fragmentada e analítica. Ao analisar a gestão ambiental através de uma abordagem sistêmica, evidenciam-se os mecanismos e métodos adotados a fim de assegurar a conservação dos recursos e elementos fundamentais para regulação da base biofísica.

\section{METODOLOGIA}

Esta é uma pesquisa básica, embasada na lógica dialética, em que a pesquisa bibliográfica fora utilizada para a fundamentação teórica deste artigo, a fim de expor conceitualmente das discussões sobre a gestão ambiental, considerado fundamentalmente compreende-la numa concepção sistêmica.

\section{RESULTADOS}

O pensamento sistêmico torna-se a chave fundamental para a construção da gestão ambiental, pois permite suas analises a partir das relações multidimensionais presente na realidade. As definições de Capra (1996) descreve que a compreensão dos sistemas vivos só podem ser desvelados dentro de um contexto maior, onde as totalidades estão integradas, ampliando assim, a interpretação dos fenômenos e das relações multidimensionais. Neste sentido, é necessário entender a natureza em sua essência para que se possa construir meios de adaptação aos processos de desenvolvimento respeitando as características e propriedades do meio natural sem esquecer a escassez dos recursos naturais.

A gestão ambiental sistêmica demonstra ser cada vez mais necessária para interpretar as problemáticas ambientais e garantir a sobrevivência dos seres vivos e das futuras gerações. É a concepção multidimensional a que melhor oferece instrumentos ao reunir os esforços das diversas ciências e incitar discussões numa visão de conjunto cada vez mais ampla e complexa.Conceber a gestão ambiental a partir de um olhar sistêmico não quer destituir o necessário conhecimento das ciências administrativas e da engenharia. A gestão ambiental sistêmica busca colocar os mesmos conhecimentos, antes fragmentados, a fim de dirimir os impasses e incongruências das quais emergem a malversação ambiental.

\section{DISCUSSÃO}

Vários pesquisadores desenvolveram contribuições sobre a construção do pensamento sistêmico, entre eles, se destaca Capra (1996) por compreender que "a ciência sistêmica mostra que os sistemas vivos não podem ser compreendidos por meio da análise" (CAPRA, 1996, p. 46). No pensamento sistêmico as fronteiras delimitadas pelo objeto são secundárias. A chave fundamental do pensamento em rede consiste nas relações como características multidimensionais presente na realidade.

O pensamento sistêmico amplia a compreensão de que os sistemas vivos só podem ser compreendidos dentro de um contexto maior, pois, "os sistemas vivos são totalidades integradas cujas propriedades não podem ser reduzidas às partes menores" (CAPRA, 1996, p. 46). Contra a fragmentação cartesiana Capra (1996) propõe desenvolver o pensamento em rede, como a unificação e a totalização da percepção do real. Para Capra (1996): 
As propriedades das partes não são propriedades intrínsecas, mas só podem ser entendidas dentro do contexto do todo maior. Desse modo, o pensamento sistêmico é pensamento "contextual"; e, uma vez que explica coisas considerando o seu contexto significa explicá-las considerando o seu meio ambiente, também podemos dizer que todo pensamento sistêmico é pensamento ambientalista (CAPRA, 1996, p. 46-47. Grifos no original).

O pensamento sistêmico contribui para esclarecer que as relações estabelecidas pelo modelo econômico capitalista e sua dinâmica de contínua evolução, reprodução e acumulação, tem-se demonstrado incompatível com a capacidade de suporte planetário por entender que os recursos naturais são infinitos. A racionalidade ambiental demonstra, por essas razões, que a crise ambiental pode também ser compreendida como o resultado da concepção reducionista, mecânica, fragmentada e analítica, por não compreender que o abismo cada vez mais amplo entre as nações desenvolvidas $\mathrm{e}$ as em desenvolvimento se equilibram por intermédio das desigualdades sociais. Os efeitos resultantes dessa relação não se restringem aos limites geográficos ou das classes sociais, pois o desenvolvimento do atual modelo econômico não consegue gerir de forma eficiente as dinâmicas para gerar o bem estar da sociedade, tampouco mantém em equilíbrio os limites ecológicos e suas potencialidades.

Somam-se às analises de Capra (1996) as desenvolvidas por Rodriguez e Silva (2013), por buscarem esclarecimento de que a crise ambiental atual consiste num dos resultados do avanço do modelo hegemônico capitalista de desenvolvimento em que uma das suas principais concepções dá-se a partir do domínio e da tentativa de controlar os tempos próprios da natureza. São estruturas extremamente organizadas e programadas sobre os meios naturais, as quais visam direcionar para que atendam as expectativas de acumulação do capital.

Rodriguez e Silva (2013) demonstram que é necessário entender a natureza em sua essência para que se possa construir meios de adaptação aos processos de desenvolvimento respeitando as características e propriedades do meio natural sem esquecer que seus recursos são escassos. Na concepção desses pesquisadores a gestão ambiental estrutura-se como uma importante ferramenta para a adequação e controle, dada pelo manejo e gerencia dos meios de exploração dos recursos naturais, econômicos e socioculturais dos sistemas ambientais naturais e territoriais.

Ao considerar as características próprias dos sistemas ambientais naturais, é essencial compreender as suas propriedades fundamentais e seus atributos complexos de organização sistêmica. Rodrigues e Silva (2013) explicam que, desde uma abordagem sistêmica, a gestão ambiental depara-se com um sistema complexo, imbuído de condições, variações, dinamicidade e resiliência. Ou seja, no estudo da gestão ambiental a abordagem lógica, não necessariamente partirá do equilíbrio, mas sim do desequilíbrio, permitindo que estas ferramentas apresentem o manejo e o monitoramento de áreas em desequilíbrio, favorecendo o conhecimento das causas e forças que originam o estado de desequilíbrio.

O planejamento ambiental e territorial, sob a influência do enfoque sistêmico e a teoria da complexidade, é concebido como uma ferramenta articulada ao processo de tomada de decisões para a gestão ambiental, no contexto de um determinado modelo e estilo de desenvolvimento. É abrangente, sistêmico, multiopcional e probabilístico e seu principal objetivo é a busca de comportamentos desejáveis dos sistemas ambientais, no contexto de um sistema dinâmico interno de adaptações às mudanças do ambiente externo (RODRIGUEZ E SILVA, 2013, p. 290). 
Rodriguez e Silva (2013) destacam essas propriedades sistêmicas como um conjunto de subsistemas de uma totalidade complexa, que consideram as restrições naturais e os processos de organização dos sistemas ambientais naturais. Partindo dessa análise, a gestão ambiental almeja proporcionar estratégias que buscam assegurar uma regulação dos sistemas ambientais naturais, contribuindo para a garantia da satisfação das necessidades básicas através do aproveitamento do potencial natural, assim determinando uma interação entre solo, vegetação e os restantes componentes do sistema

A gestão ambiental concebido a partir de um olhar sistêmico não quer destituir o necessário conhecimento das ciências administrativas. Muito pelo contrário, utilizar de forma sistêmica todos os conhecimentos dela visando à redução dos impactos das atividades econômicas sobre os recursos ambientais. Adaptar os mesmos conhecimentos colocando-os a serviço da gestão ambiental como um processo de monitoramento dos impactos sobre o ecossistema. Com isso tentar entender as relações do homem com a natureza e a necessidade do respeito aos ciclos de renovação do ecossistema, estabelecendo um equilíbrio harmônico sem com isso obstaculizar o desenvolvimento econômico.

Os desdobramentos da gestão ambiental a partir da visão sistêmica analisada por Rodriguez e Silva (2013) contribuem para ampliar a compreensão sobre as análises de Coimbra (2004). A gestão sistêmica ambiental demonstra ser cada vez mais necessária para interpretar as problemáticas ambientais e garantir a sobrevivência dos seres vivos e das futuras gerações, como esclareceu Coimbra (2004):

É indispensável (re) pensar o mundo natural como uma realidade concreta, valiosa em si e por si, isto é, dotada de valor intrínseco. Isso significa também pensar em um meio ambiente como realidade histórica, em seus aspectos naturais acrescidos das transformações feitas pelo ser humano (indivíduo e sociedade), como também uma realidade social. No estágio de ocupação do espaço e da civilização tecnológica, pouco ou quase nada se pode encontrar do mundo natural em estado puro. Isso conduz à necessidade de uma visão multifocal do meio ambiente e à aceitação da complexidade como hipótese de trabalho (COIMBRA, 2004, p. 525 e 526. Grifos no original).

Coimbra (2004) contextualiza a discussão da questão ambiental com uma visão crítica a respeito das concepções reducionistas formulados para conceituar a realidade ambiental e a defesa dos sistemas naturais. Para ele a concepção multidimensional é a que melhor oferece instrumentos ao reunir os esforços das diversas ciências e incitar discussões numa visão de conjunto, de forma sistêmica e complexa, apropriada e adequada para ampliar a compreensão das problemáticas ambientais.

Na discussão de uma gestão ambiental a partir da visão sistêmica, considerando a base biofísica como um sistema complexo, emerge a necessidade das abordagens do conhecimento multidimensional arraigado ao pensamento humanista ao priorizar sempre o resgate e o desenvolvimento dos valores e ideais humanitários. É necessário "um novo humanismo que nos ensine a ser e agir com sabedoria no mundo concreto em que vivemos" (COIMBRA, 2004, p. 531. Grifos no original), capaz de incutir na humanidade o sentimento, valores e ideais de um ser humano como um ser ambiental.

Ao trabalhar a gestão ambiental com enfoque sistêmico é importante entender os constitutivos do meio ambiente, bem como, respeitar os dilemas e mistérios que ainda envolve a natureza. Coimbra (2004) relata que o meio ambiente é constituído como um gigantesco ecossistema - "é tudo que vai à volta, e tudo o que nos rodeia" (COIMBRA. 2004, p. 533). Os esforços para compreensão e estudos da questão ambiental não podem serem analisados apenas 
por algumas ciências de forma isolada, mas promover um desenvolvimento cientifico multidisciplinar.

As análises de Rodriguez e Silva (2013) e Coimbra (2004) impulsionam o debate da gestão ambiental e colaboram ao ampliarem e a aprofundarem a imprescindibilidade dessas discussões como condição para se aproximar da complexidade da questão ambiental. Complexidade também analisada por Santos (2004), ao tratar do planejamento ambiental. Para Santos (2004), o planejamento acompanha desde a gênese da organização da humanidade em comunidades, em que buscavam ordenar o território a partir dos aspectos ambientais. Nesse processo de ordenamento "os homens planejavam seu espaço buscando atender preceitos religiosos, de estética e de conforto" (SANTOS, 2004, p. 16).

À medida que avança o desenvolvimento são alteradas as relações entre o ser humano e a natureza, principalmente, ao incitar as transformações a partir da concepção de que no centro do desenvolvimento encontra-se apenas o ser humano. Esse antropocentrismo consiste numa das justificativas do avanço tecnológico e da tecnociência os quais compõem um dos dois pilares do modo de produção capitalista. Com a expansão do modo de produção capitalista há um intenso processo com o qual ocorre uma profunda desestabilização dos sistemas ambientais, ampliando de forma considerável a materialização da economia, a concentração de poder e o acumulo de capital, resultando em um quadro de violação e deterioração da biosfera sem precedentes registrados.

A malversação dos recursos ambientais resulta em sérios comprometimentos dos componentes ambientais, dentre elas a devastação das paisagens, tornando as superfícies territoriais vulneráveis às intempéries, erosões, lixiviações, contaminações, acidificação, desmineralização dentre outros fatores preponderantes para uma eficiente regulação. Este é o modo e as reações, com as quais, o capital trata quem ou o que lhe apresenta limite. Por não admitir limites, o capital age violando, e acima de tudo ignorando as consequências cruéis e devastadoras da base natural da existência humana.

Na medida em que os limites da produção, extração e malversação começaram a ser questionados e as evidências de um colapso ambiental foram se intensificando, ensejou-se a necessidade por estabelecer ferramentas capazes de proporcionar e orientar um adequado uso, controle e proteção do meio ambiente, considerando as especificidades e as características locais. Neste contexto a formatação do planejamento ambiental com abordagem sistêmica, favorece os conceitos da análise integrada da paisagem, assim subsidiando a gestão dos recursos naturais e a análise da capacidade de suporte da natureza e as suas vocações econômicas locais.

Para Santos (2004) o planejamento ambiental deve se estabelecer em três eixos: técnico, social e político, objetivando reorganizar o ambiente. Dessa forma, o planejamento ambiental parte da desorganização para organização, ou seja, o planejamento ambiental "tem o papel de estabelecer as relações entre os sistemas ecológicos e os processos da sociedade, das necessidades socioculturais a atividade e interesses econômicos, a fim de manter a máxima integridade possível dos seus elementos e componentes" (SANTOS, 2004, p. 28).

Neste contexto uma das condicionantes mais importantes da gestão ambiental é o processo de planejamento estruturado de forma sistêmica potencializando a valorização da análise multidimensional ao priorizar relações não apenas constituída por recursos e elementos bióticos e abióticos, mas também das relações existentes dentro do sistema, as quais merecem destaques as relações de transformação resultantes das ações antrópicas. A gestão ambiental sistêmica tende a considerar as características ambientais, para poder alcançar e assegurar uma regulação dos sistemas ambientais naturais, contribuindo para a garantia da satisfação das necessidades básicas através do aproveitamento do potencial natural ao dinamizar interações entre solo, vegetação e demais componentes do sistema. 


\section{CONCLUSÃO}

Os levantamentos reunidos neste trabalho abordam introdutoriamente contribuições sobre a construção do pensamento sistêmico, buscando ampliar a compreensão de que os sistemas vivos só podem ser compreendidos dentro de um contexto maior. Diferentemente do paradigma cientifico cartesiano, em que a observação da natureza exposta é conduzida por modelos e métodos de questionamento, em que as descrições são objetivas e fundamentalistas; o pensamento sistêmico demonstra-se como um novo paradigma, em que implica na compreensão do processo do conhecimento, ou seja, em observar a natureza como ela é, sendo uma teia interconectada de relações.

Ao optar pela gestão ambiental partindo do enfoque sistêmico, a teoria dos sistemas permite uma considerável contribuição aos estudos, por valorizar as propriedades fundamentais dos sistemas naturais. A gestão ambiental concebido a partir de um olhar sistêmico não quer destituir o necessário conhecimento das ciências administrativas. Muito pelo contrário, utilizar de forma sistêmica todos os conhecimentos dela visando à redução dos impactos das atividades econômicas sobre os recursos ambientais. Adaptar os mesmos conhecimentos colocando-os a serviço da gestão ambiental como um processo de monitoramento dos impactos sobre o ecossistema. Com isso tentar entender as relações do homem com a natureza e a necessidade do respeito aos ciclos de renovação do ecossistema, estabelecendo um equilíbrio harmônico sem com isso obstaculizar o desenvolvimento econômico.

Analisou-se que na medida em que o modo de produção capitalista se expande sobre os recursos naturais ele provoca uma profunda desestabilização dos sistemas ambientais, ampliando as esferas de violação e deterioração da biosfera. As tecnologias e modelos de gerenciamento ambiental desenvolvidas pelo capital para direcionar seu atendimento às expectativas de acumulação não são capazes de reparar os danos avassaladores da malversação dos recursos e elementos ambientais.

Por fim, a gestão ambiental sistêmica demonstra ser cada vez mais necessária para interpretar as problemáticas ambientais e garantir a sobrevivência dos seres vivos e das futuras gerações. É a concepção multidimensional a que melhor oferece instrumentos ao reunir os esforços das diversas ciências e incitar discussões numa visão de conjunto cada vez mais ampla e complexa. Conceber a gestão ambiental a partir de um olhar sistêmico não quer destituir o necessário conhecimento das ciências administrativas e da engenharia. A gestão ambiental sistêmica busca colocar os mesmos conhecimentos, antes fragmentados, a fim de dirimir os impasses e incongruências das quais emergem a malversação ambiental.

\section{REFERÊNCIAS}

CAPRA, Fritjof. A teia da Vida: Uma nova compreensão cientifica dos sistemas vivos. 11 ed. SP: Editora Cultrix, 1996.

COIMBRA, J. A. A. Linguagem e Percepção Ambiental. In: PHILIPPI JR, A.; ROMÉRO, M. A.; BRUNA, G. C. (Ed.). Curso de Gestão Ambiental. Barueri, São Paulo: Manole, 2004.

RODRIGUEZ, J. M .M; SILVA, E. V. Planejamento e Gestão Ambiental: subsídio da geoecologia das paisagens e da teoria geossistêmica. Fortaleza: Edições UFC, 2013.

SANTOS, R. F. Planejamento ambiental: teoria e prática. São Paulo: Oficina dos Textos, 2004. 